\title{
Experimental investigation into gas production from methane hydrate in sediment by depressurization in a novel pilot-scale hydrate simulator
}

\author{
Xiao-Sen Li ${ }^{\text {a,b,* }}$, Bo Yang ${ }^{\text {a,b,c }}$, Yu Zhang ${ }^{\text {a,b }}$, Gang Li ${ }^{\text {a,b }}$, Li-Ping Duan ${ }^{\text {d }}$, Yi Wang ${ }^{\text {a,b,c }}$, Zhao-Yang Chen ${ }^{\text {a,b }}$, \\ Ning-Sheng Huang ${ }^{\text {a,b }}$, Hui-Jie $\mathrm{Wu}^{\mathrm{a}, \mathrm{b}}$ \\ a Key Laboratory of Renewable Energy and Gas Hydrate, Guangzhou Institute of Energy Conversion, Chinese Academy of Sciences, Guangzhou 510640, PR China \\ ${ }^{\mathrm{b}}$ Guangzhou Center for Gas Hydrate Research, Chinese Academy of Sciences, Guangzhou 510640, PR China \\ ${ }^{\mathrm{c}}$ Graduate University of Chinese Academy of Sciences, Beijing 100083, PR China \\ ${ }^{\mathrm{d}}$ Institute of Scientific and Technical Information of China, Beijing 100038, PR China
}

\section{A R T I C L E I N F O}

\section{Article history:}

Received 28 October 2011

Received in revised form 3 January 2012

Accepted 5 January 2012

Available online 29 January 2012

\section{Keywords:}

Hydrate dissociation

Sediment

Three-dimension

Production

Depressurization

Reservoir size

\begin{abstract}
A B S T R A C T
The gas production behavior from methane hydrate in the sediment by depressurization was investigated in a novel pilot-scale hydrate simulator (PHS), a three-dimensional pressure vessel of 117.8 L. Experimental results are compared with those in a cubic hydrate simulator (CHS) with the effective volume of $5.8 \mathrm{~L}$ to reveal the dependence of the production behavior on the size of the hydrate reservoir. Results show that the gas production processes in the two simulators consist of three periods: the free gas production, mixed gas (free gas and gas dissociated from the hydrate) production and gas production from hydrate dissociation. The first and second periods are mainly controlled by the pressure reduction rate. The heat conduction from the ambient is main driving force to dissociate the hydrate in the third period. The cumulative gas production in the third period with the PHS and CHS is much higher than those in the first and second periods. However, the gas production rate in the period is low. The duration for gas production with the PHS is approximately 20 times as many as that with the CHS. Water production behavior with the PHS is different with that with the CHS during the gas production. The system temperature change tendency with the PHS is the same with that with the CHS during the gas production. The unique difference is that there is also a temperature rise period with the CHS.
\end{abstract}

(c) 2012 Elsevier Ltd. All rights reserved.

\section{Introduction}

Fossil fuels currently provide about $85 \%$ of the world's commercial energy needs [1]. On a relative basis, natural gas (NG) is the fastest growing energy source in the world [2]. Gas hydrates are ice-like inclusion compounds formed from water and gas molecules at high pressures and low temperatures. Over the last decade, there has been a dramatic increase in gas hydrate research, such as natural gas production, carbon dioxide sequestration and separation $[3,4] .1 \mathrm{~m}^{3}$ of methane hydrate will release approximately $170 \mathrm{~m}^{3}$ of methane gas at standard temperature and pressure. Natural gas hydrate (NGH) is being recognized as a potential strategic energy resource [5], it is because NGH is vastly distributed throughout both the marine and permafrost areas [6,7]. A variety of methods have been proposed to exploit this energy resource: (a) thermal stimulation; (b) depressurization; (c) injection of inhibitors [8]. Depressurization is a gas recovery method

\footnotetext{
* Corresponding author at: Key Laboratory of Renewable Energy and Gas Hydrate, Guangzhou Institute of Energy Conversion, Chinese Academy of Sciences, Guangzhou 510640, PR China. Tel.: +86 20 87057037; fax: +86 2087034664.

E-mail address: lixs@ms.giec.ac.cn (X.-S. Li).
}

to dissociate methane hydrate $(\mathrm{MH})$ through altering the pressure value in the reservoir to a point below the equilibrium value corresponding to the reservoir temperature [9]. Depressurization method is used most commonly because of its highest energy profit ratio. Unlike the thermal stimulation or the inhibitor injection method, the depressurization method does not require any additional costs. Thus, it has been applied for gas production from the Messoyakha hydrate gas reservoir in Russia [10]. Earlier studies indicated that the depressurization method is the most promising dissociation method in the majority of hydrate deposits because of its simplicity, its technical and economic effectiveness, the fast response of hydrates to the rapidly propagating pressure wave, the near-incompressibility of water, and the large heat capacity of water [11-13].

Recently, a variety of the mathematic and experimental investigations into the hydrate production behaviors by depressurization have been undertaken. Sun et al. [14] developed a one-dimensional numerical model to simulate two regimes of gas production from the sediments containing methane hydrates by depressurization. Song and Liang [15] developed a two-dimensional axisymmetric simulator for gas production from hydrate reservoirs and simulated the process of laboratory-scale hydrate decomposition by 
depressurization and found the high surrounding temperature and low outlet valve pressure may increase the rate of hydrate dissociation. Tang et al. [16] carried out the experimental work on the methane gas production from an experimental-scale hydrate reservoir by depressurization and used the hydrate reservoir simulator, Tough-Fx/Hydrate, to simulate the gas production behavior. The results suggested that the hydrate dissociation kinetics has a great effect on the gas production behavior for the laboratory-scale hydrate-bearing core. However for a field-scale hydrate reservoir, the flow ability dominates the gas production behavior and the effect of hydrate dissociation kinetics on the gas production behavior can be neglected. Oyama et al. [17] used an artificial sedimentary core and performed several depressurization experiments under various production pressure conditions and developed a numerical model for methane hydrate dissociation process in the porous media to analyze the physical phenomena in a methane hydrate reservoir. Lee et al. [18] designed and set up an experimental apparatus to analyze the dissociating phenomena of the hydrate in the porous rock. Depressurization experiments were carried to investigate into the dissociation characteristics and the productivity of the dissociated gas. The results verify that the degree of depressurization is a significant factor influencing the gas production rate in a hydrate reservoir. Haligave et al. [19] reported the recovery of methane from a variable-volume bed of silica sand and hydrate by depressurization. They found that the gas production consists of the two periods. The rate of gas recovery is strongly dependent on the silica sand bed size during the first stage, and depends weakly on the size during the second stage. Sakamoto et al. [20] conducted the experimental studies on the dissociation of methane hydrate and gas production behaviors by depressurization in the sediments. They investigated into the horizontal radial flows in the porous media during methane hydrate dissociation under a variety of vertical loads in order to reproduce field conditions in the real methane hydrate sediments. It was found that the methane hydrate dissociation consisted of two stages due to the latent heat of sediments and thermal conduction. Kono et al. [21] measured the dissociation rates of methane gas hydrate in various custom-designed porous sediments by the depressurizing method, and derived the kinetic dissociation rate equation. They reported that the dissociation rate can be adjusted by controlling the sediment properties. So far, the experimental studies on methane dissociation and gas production by depressurization are carried out using the small one-dimensional or two-dimensional experimental apparatuses [14-21].

Because there are some differences of the control mechanisms for gas hydrate production with the lab-scale hydrate reservoir and the field-scale hydrate reservoir [16], it is difficult to test the validity of numerical simulation schemes for hydrate dissociation using the experimental data with a small one-dimensional or two-dimensional experimental apparatus. Thus, it is significant to investigate into the potential influence of the size of the experimental reservoir on the production behavior of the hydrate by depressurization. On the other hand, the real hydrate reservoir is a three dimensional (3D) reservoir. In order to investigate into the gas production characteristics in a 3D reservoir, it is very significant to simulate the hydrate dissociation behaviors in the 3-D experimental apparatus. Recently, we have reported the investigation into the gas production behavior from methane hydrate in the porous sediment by depressurization in a three-dimensional cubic hydrate simulator (CHS) with the effective volume of $5.8 \mathrm{~L}$ [22]. The results show that the gas production process consists of three periods: the free gas production, mixed gas (free gas and gas dissociated from the hydrate) production and gas production from the hydrate dissociation. The temperature changes in the near-well region and the far-from-well region in the 3D hydrate reservoir during gas production contain the five stages and four stages, respectively. In the gas production process, the resistances in the hydrate reservoir change with the hydrate dissociation and the gas and water flows. The gas hydrate dissociation in the gas production process is mainly controlled by the rate of the pressure reduction in the system and the heat supplied from the ambient. The water production has been almost completed in the free gas production process.

In this work, the pilot-scale hydrate simulator (PHS), a novel three-dimensional 117.8-L pressure vessel, has been developed for the investigation into the gas production behavior of the methane hydrate in the sediment by using depressurization method. The experiments were performed at the hydrate saturation of $30 \%$ and environmental temperature of $281.15 \mathrm{~K}$. These conditions simulate the ones of the hydrate reservoir in the Shenhu Area, South China Sea. The gas production pressure is $4.7 \mathrm{MPa}$. In addition, the investigation into the potential dependence of the production behavior on the size of the hydrate reservoir was carried out by comparison with the results obtained from using a threedimensional medium-size cubic hydrate simulator (CHS) with the effective volume of $5.8 \mathrm{~L}$ [22].

\section{Experimental section}

\subsection{Experimental apparatus}

The schematic of the experimental apparatus used in this work is shown in Fig. 1. The PHS, a novel 117.8-L pressure vessel, is made of stainless steel. The PHS can withstand pressures of up to $30 \mathrm{MPa}$. The low temperatures required for the experiments are obtained by placing the whole apparatus encircling a water jacket $(-15-$ $\left.30^{\circ} \mathrm{C}, \pm 0.1^{\circ} \mathrm{C}\right)$ inside the walk-in cold room $\left(-8{ }^{\circ} \mathrm{C}-30^{\circ} \mathrm{C}, \pm 2{ }^{\circ} \mathrm{C}\right)$. Fig. 2 shows the schematic of the layers and the well design of the PHS. As shown in Figs. 1 and 2, there are three horizontal layers named Layers A-A, B-B and C-C inside the vessel, which equally divide the vessel into four regions. The distance between Layer A-A and Layer B-B is $150 \mathrm{~mm}$, a quarter of the internal length of the PHS, which is the same with that between Layer B-B and Layer $\mathrm{C}-\mathrm{C}$, while Layer B-B is in the middle of the PHS. As shown in Fig. 2, a 9-spot distribution of the vertical wells is fixed in the top flange (the Top Surface) of the PHS, and there are three vertical wells at each spot $(\mathrm{V} 1, \mathrm{~V} 2, \ldots, \mathrm{V} 9)$, which extend into the vessel to Layers $\mathrm{A}-\mathrm{A}, \mathrm{B}-\mathrm{B}$, and $\mathrm{C}-\mathrm{C}$, respectively. As a typical example, it is shown in Fig. 2 that Wells V5A, V5B and V5C are all placed on Spot V5, and the bottoms of these wells are on Layers A-A, B-B and C-C, respectively. Wells V5A, V5B and V5C are at the axis of the PHS. In general, a total of 27 vertical wells are distributed in the PHS, and the wells on Spots V1, V3, V7 and V9 are all immediately close to the inside edge of the PHS, and the bottom of each well is right on the corresponding layer.

As shown in Fig. 2, in the Right Surface of the PHS, 3 horizontal wells, Wells $\mathrm{HA}, \mathrm{HB}$ and $\mathrm{HC}$, are inserted into Spots $\mathrm{H} 1, \mathrm{H} 2$ and $\mathrm{H} 3$ on Layers A-A, B-B and C-C, respectively. Each horizontal well is extended to the inside surface of the Left Surface of the PHS. Fig. 3 shows the schematic of the distribution of the thermometers (the temperature measuring spots) in the PHS. There are 49 thermometers evenly distributed on each layer, with a total of 147 spots in the PHS. In other words, on each layer (Layers A-A, B-B and $C-C$ ), it is a 49-spot distribution of the thermometers (T1T49), with T25 at the center and T1, T7, T43, and T49 at the corner. The thermometers at the same spots are distinguished by the different layers, for example, as shown in Fig. 3, the 43th thermometer on Layer A-A is called T43A, and those on Layer B-B and Layer $\mathrm{C}-\mathrm{C}$ are $\mathrm{T} 43 \mathrm{~B}$ and $\mathrm{T} 43 \mathrm{C}$, respectively. The distribution of the resistance ports is the same with that of the thermometers, with the corresponding name of R1-R49. As shown in Fig. 3, the 43th 


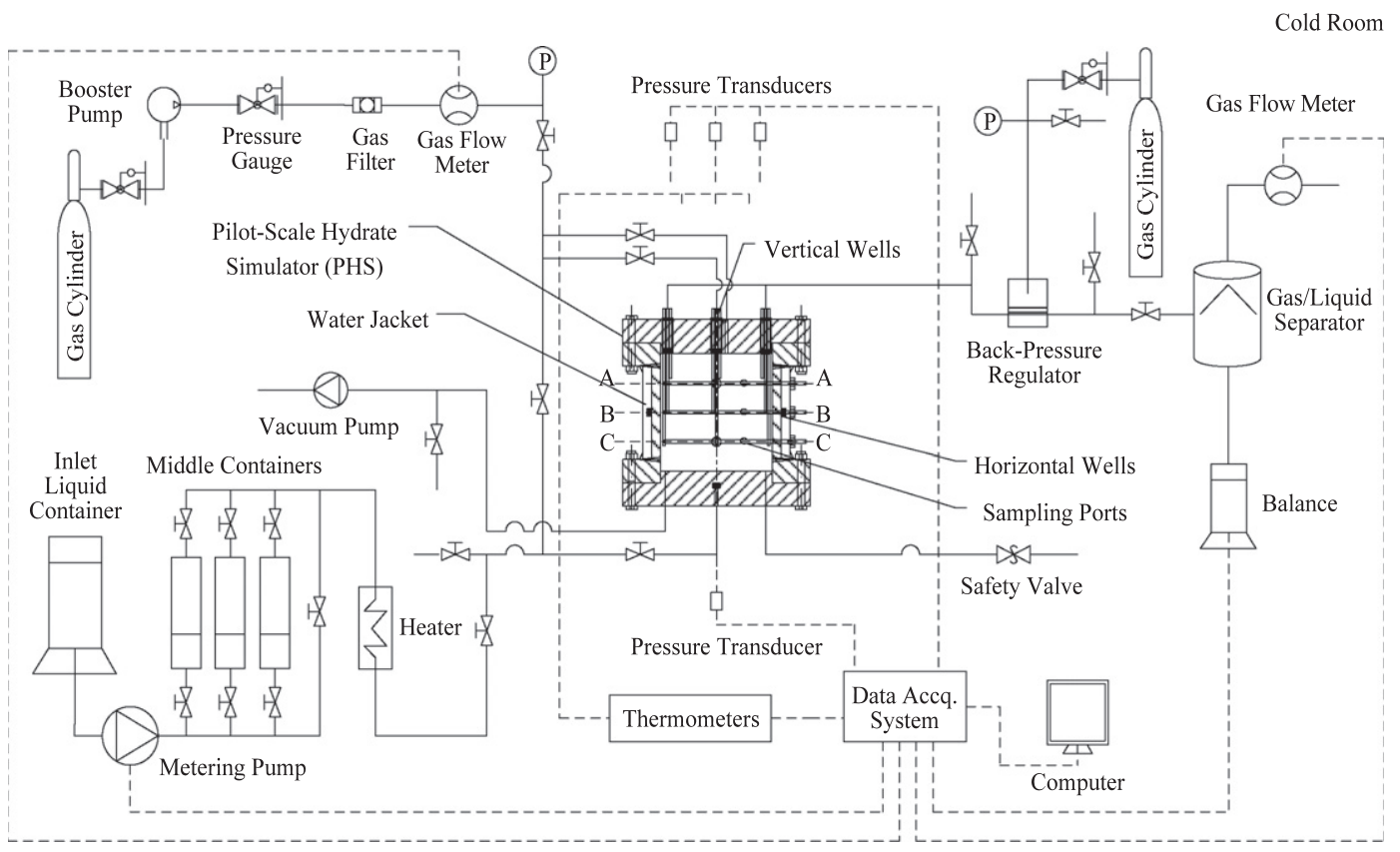

Fig. 1. Schematic of experimental apparatus.

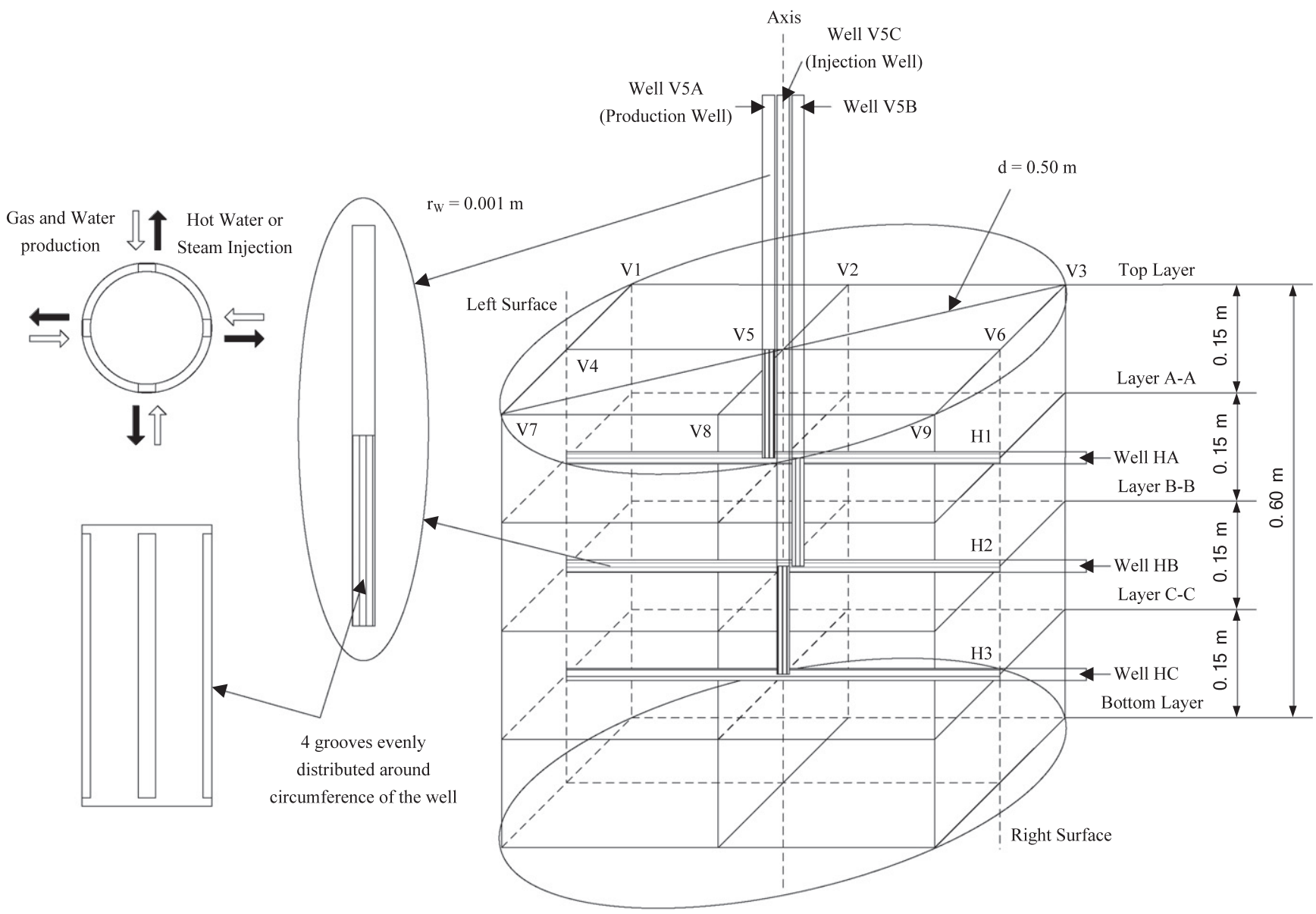

Fig. 2. Schematic of layers and well design of PHS. 


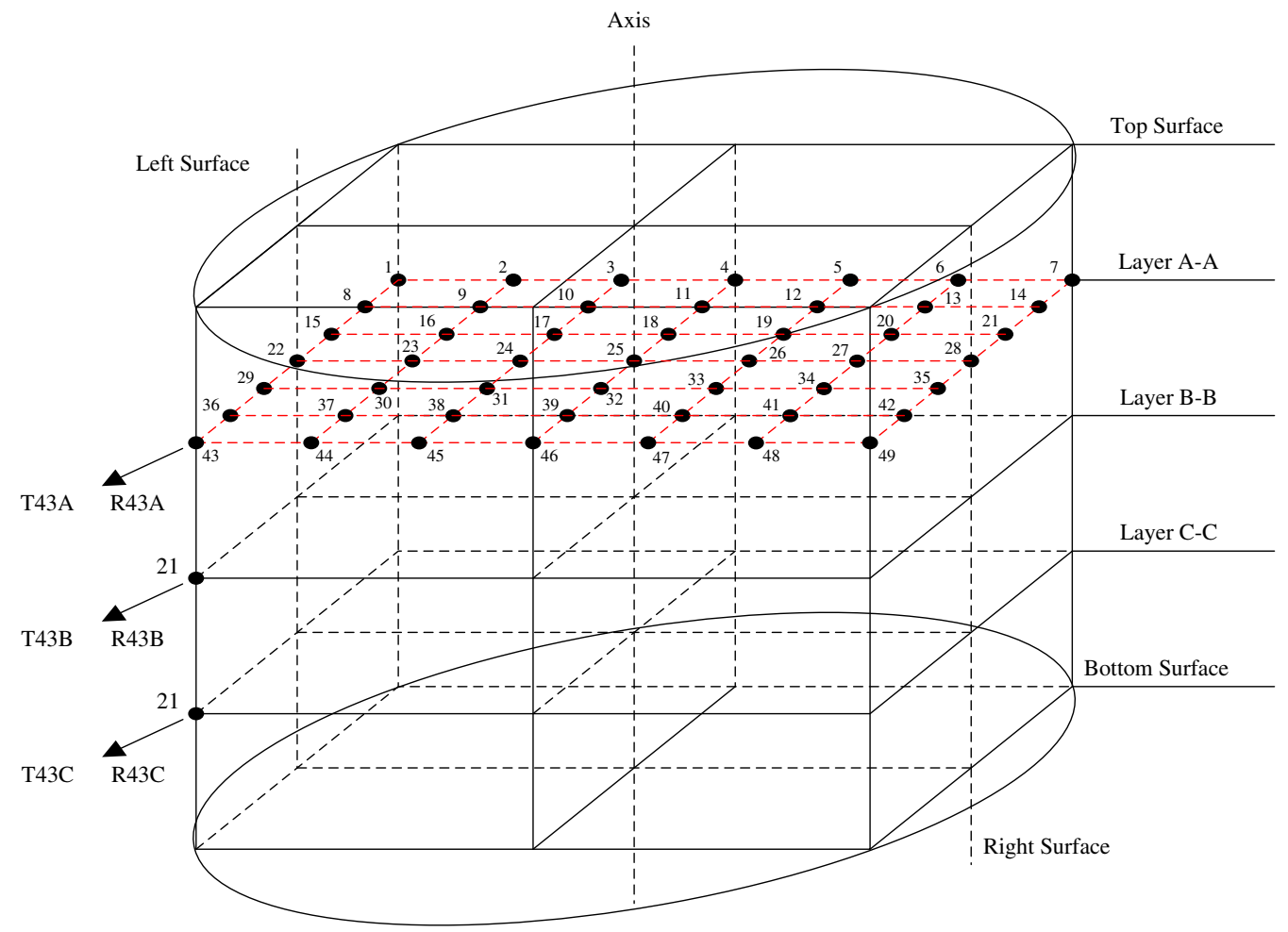

Fig. 3. Schematic of distributions of thermometer and resistance ports in PHS

resistance port on Layer A-A is called R43A, and those on Layer B-B and Layer $C-C$ are R43B and $\mathrm{R} 43 \mathrm{C}$, respectively.

A pressure transducer at the center of the bottom of the PHS (the "Inlet Pressure") is used to measure the pressure of the base of the Hydrate-Bearing Layer (HBL). And another pressure transducer (the "Outlet Pressure") is placed at the production well. A sampling port is placed at on each layer. A safety valve and a vacuum pump are connected to the PHS.

The thermometers are Pt100 with the range of -20 to $200{ }^{\circ} \mathrm{C}$, $\pm 0.1^{\circ} \mathrm{C}$. The pressure transducers are TRAGAG NAT 8251.84.2517, $0-40 \mathrm{MPa}, \pm 0.04 \mathrm{MPa}$. Two gas flow meters, which are used to measure the cumulative gas injected into the PHS, the gas production rate and the cumulative gas produced from the vessel, are both of D08-8C and D07-9E, 0-100 L/min, $\pm 2 \%$ from "Seven Star Company". The thermometers, pressure transducers and gas flow meters are calibrated using a mercury thermometer with the tolerance of $\pm 0.01^{\circ} \mathrm{C}$, a pressure test gauge with the error of $\pm 0.05 \%$, and a wet gas meter with the accuracy of $\pm 10 \mathrm{ml} / \mathrm{min}$, respectively. Resistance is measured by TH2810B resistivity meter from "Tonghui Company". A metering pump "Beijing Chuangxintongheng" HPLC P6000 with the range of $250 \mathrm{ml} / \mathrm{min}$ can withstand the pressures of up to $20 \mathrm{MPa}$. An inlet liquid container with the inner volume of $10 \mathrm{~L}$ is used to contain the deionized water used in the experiments. In order to protect the metering pump from corrosion by the hot brine or the chemicals, 3 middle containers are used for the solution injection, and the inner volume of each container is $4 \mathrm{~L}$. A back-pressure regulator (the pressure range of $0-30 \mathrm{MPa}$, $\pm 0.02 \mathrm{MPa}$ ) connected to the outlet of the PHS is used to control the pressure of the production well. An electronic balance, used to measure the mass of liquid produced from the production wells, is ALH-30 from Guangzhou Zhicheng Electronic Scale company, 0$30 \mathrm{Kg}, \pm 2 \mathrm{~g}, \mathrm{RS} 232$ interface. The data acquisition system records the temperature, the pressure, the amount of the cumulative gas produced from the vessel, the gas production rate and the liquid production rate. In this work, the methane gas with its purity of $99.9 \%$ is used.

\subsection{Well design}

Fig. 2 shows the design of the vertical and horizontal wells in the PHS. As shown in Fig. 2, there are four grooves evenly distributed along the circumference of each vertical well, thus as Well V5A, Well V5B, and Well V5C. The grooves on Well V5A extended from the internal surface of the Top Surface of the PHS to Layer A-A, while those on Well V5B is from Layer A-A to Layer B-B, and the top and the bottom of the grooves on Well V5C are Layer $\mathrm{B}-\mathrm{B}$ and Layer $\mathrm{C}-\mathrm{C}$, respectively. The gas and water production from the PHS are both through the grooves, as shown in Fig. 2. Previous numerical study has shown a similar well design [23], in which there are eight grooves evenly distributed along the circumference of the single horizontal well. Comparing with using the single well with hot brine injection and gas production simultaneously [13] and the well with hot water circulating inside the wellbore [23,24], this well design is much simpler and practically feasible. Vertical wells at the axis of the PHS (Well V5A, Well V5B, and Well V5C) are used simultaneously as Well V5, which is the production well during gas production by depressurization in this work.

\subsection{Experimental procedure}

During the experiment, the raw dry quartz sands with a size range between 300 and $450 \mu \mathrm{m}$ are tightly packed in the vessel, and then the vessel is evacuated twice to remove air in it with a vacuum pump. The quartz sand in the vessel is wetted to saturation with distilled water at atmospheric pressure using a metering pump. The sand sediment is considered as saturation when the rate of water produced from the vessel is equal to that of the water injected. By measurement, $32.20 \mathrm{~L}$ deionized water is injected into the vessel. The temperature of the water bath is then set to the predetermined temperature required for the gas hydrate synthesis, which is $281.15 \mathrm{~K}$ in the work. Then the methane gas is injected into the vessel until the pressure in the vessel reaches 
approximately $20 \mathrm{MPa}$. The inlet and outlet valves of the PHS are closed to keep the system in a constant volume condition. When the hydrate formation starts, the pressure inside the PHS decreases. When the pressure drops to the desired value (8.27 MPa), the production experiment is carried out by depressurization. The hydrate saturation (the volume ratio of the hydrate and available pore space) in the vessel is approximately $30 \%$, which is calculated by the method given by Li et al. [25]. The water and gas saturations are $44 \%$ and $26 \%$ respectively.

The following procedure is used to investigate into the dissociation characteristics of methane hydrate by depressurization. Firstly, the backpressure regulator is set to the desired pressure value, which is $4.7 \mathrm{MPa}$. Then the outlet valve is opened to make the pressure in the vessel decrease to the desired value, which is the gas production pressure. The pressure decreases gradually to the set pressure value, and the gas hydrate begins to be decomposed under this situation. The gas and water are produced from the vessel through the outlet of the production well. The vertical wells of V5A, V5B, and V5C at the axis of the PHS are used as the production well. When there is little gas release, it is considered as the end of the gas production. During the production experiment, the temperatures and pressures in the vessel, the gas and the water production rates are recorded at $20 \mathrm{~s}$ intervals.

\section{Results and discussion}

In the work, we carried out the investigation into the gas production behavior from methane hydrate in the sediment by depressurization with the PHS, and the results were compared with those with the CHS, which were obtained from our pervious work [22]. The experimental conditions with the PHS and CHS are similar, which are given in Table 1.

\subsection{Pressure change}

Fig. 4 shows the change of the system pressure along with the average system temperature in the PHS during the experiment. Due to the high porosity and permeability of the sediment, the pressures at the different measuring points in the PHS have little discrepancy. Thus, the pressure at any point in the PHS can be taken as the system pressure. As shown in Fig. 4, the pressure

Table 1

Experimental conditions and results with the PHS and CHS.

\begin{tabular}{|c|c|c|c|c|}
\hline & & & PHS & CHS \\
\hline & & Effective volume (L) & 117.8 & 5.8 \\
\hline & & Production pressure (MPa) & 4.7 & 4.5 \\
\hline & & Hydrate saturation & $30 \%$ & $33 \%$ \\
\hline & & Ambient temperature $\left({ }^{\circ} \mathrm{C}\right)$ & 8.0 & 8.0 \\
\hline & & Size of quartz sand $(\mu \mathrm{m})$ & $300-450$ & $300-450$ \\
\hline \multicolumn{5}{|c|}{ Gas production period } \\
\hline Free gas & & $R_{S}\left(\mathrm{~L} \mathrm{~min}^{-1} \mathrm{~L}^{-1}\right)$ & 0.185 & 0.602 \\
\hline Mixed gas & & $R_{S}\left(\mathrm{~L} \mathrm{~min}^{-1} \mathrm{~L}^{-1}\right)$ & 0.249 & 0.678 \\
\hline \multirow[t]{12}{*}{ Dissociated gas } & $x=10 \%$ & $R_{S}\left(\mathrm{~L} \mathrm{~min}^{-1} \mathrm{~L}^{-1}\right)$ & 0.0709 & 0.2400 \\
\hline & & $t(\min )$ & 21 & 3.3 \\
\hline & $x=20 \%$ & $R_{S}\left(\mathrm{~L} \mathrm{~min}^{-1} \mathrm{~L}^{-1}\right)$ & 0.0238 & 0.1480 \\
\hline & & $t(\min )$ & 125 & 10.8 \\
\hline & $x=30 \%$ & $R_{S}\left(\mathrm{~L} \mathrm{~min}^{-1} \mathrm{~L}^{-1}\right)$ & 0.0161 & 0.1296 \\
\hline & & $t(\min )$ & 278 & 18.5 \\
\hline & $x=40 \%$ & $R_{S}\left(\mathrm{~L} \mathrm{~min}^{-1} \mathrm{~L}^{-1}\right)$ & 0.0086 & 0.0888 \\
\hline & & $t(\min )$ & 692 & 36 \\
\hline & $x=60 \%$ & $R_{S}\left(\mathrm{~L} \mathrm{~min}^{-1} \mathrm{~L}^{-1}\right)$ & 0.0045 & 0.0551 \\
\hline & & $t(\min )$ & 1965 & 87 \\
\hline & $x=80 \%$ & $R_{S}\left(\mathrm{~L} \mathrm{~min}^{-1} \mathrm{~L}^{-1}\right)$ & 0.0033 & 0.0405 \\
\hline & & $t(\min )$ & 3544 & 158 \\
\hline \multicolumn{2}{|c|}{ Depressurizing period } & $M_{w}\left(\mathrm{~g} \mathrm{~L}^{-1}\right)$ & 9.11 & 161.30 \\
\hline \multicolumn{2}{|c|}{ Steady pressure period } & $M_{w}\left(\mathrm{~g} \mathrm{~L}^{-1}\right)$ & 3.07 & 1.22 \\
\hline
\end{tabular}

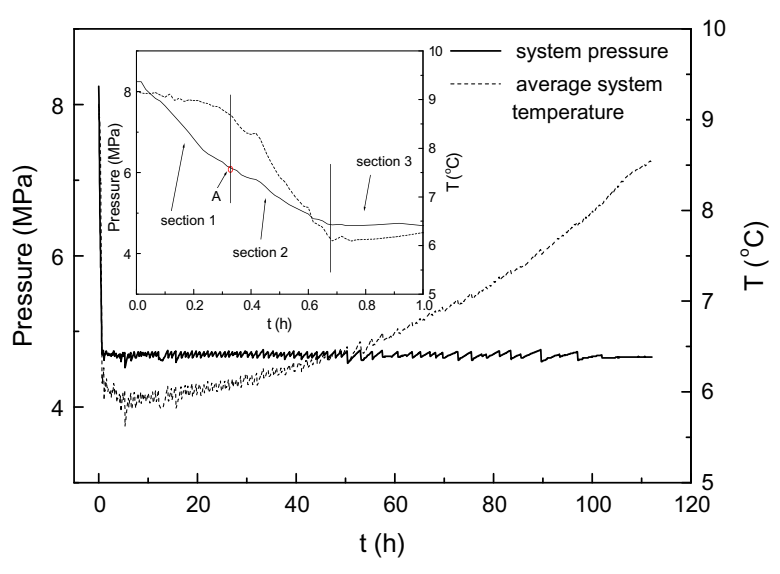

Fig. 4. System pressure and average temperature changes during experiment with PHS.

change consists of three periods. The first period is between 0 and $0.33 \mathrm{~h}$, which represents the process of the free gas release. In this period, the free gas in the vessel is released, the pressure in the vessel decreases rapidly, and it is still higher than the equilibrium hydrate dissociation pressure. Thus, the average temperature in the vessel has no significant change and only decreases slightly due to the Joule-Thomson effect [16]. The second stage is between 0.33 and $0.67 \mathrm{~h}$. In this stage, the system pressure continuously decreases, and is lower than the equilibrium hydrate dissociation pressure. Therefore, the hydrate begins to be dissociated, and the pressure reduction rate decreases during this period, compared with that in the first period. Meanwhile, the average temperature in the hydrate reservoir decreases remarkably on account of the endothermic reaction of the hydrate dissociation. It is noted that, as shown in Fig. 4, the initial point of the second stage is point A. The system pressure and the average temperature corresponding to point A are $6.10 \mathrm{MPa}$ and $281.8 \mathrm{~K}$, respectively. Using the fugacity model of Li et al. [26], the equilibrium hydrate dissociation pressure in the sediment at the temperature at point $\mathrm{A}$ is calculated. The calculated value is $6.12 \mathrm{MPa}$, which is found to be in quite good agreement with the above experimental data. This illustrates that the pressure corresponding to point $A$ is almost equal to the equilibrium hydrate dissociation pressure at the corresponding average temperature at point $\mathrm{A}$. The third period is from approximately $0.67 \mathrm{~h}$ to the end of the experiment. In this period, the pressure in the vessel remains constant, and is the same with the set production pressure. The hydrate is dissociated continuously until the dissociation is completed and the average temperature gradually increases due to the heat transfer from the ambient. The similar phenomena can be observed with the CHS.

\subsection{Gas production}

Fig. 5 shows the cumulative gas production during the experiments with the PHS and CHS. The gas production processes with the PHS and CHS are divided into the three periods, the free gas release, the mixed gas production and the gas production from hydrate dissociation [22]. As a typical example of the experiment with the PHS, shown in Fig. 5, the rate of the gas production is relatively high and almost constant in the first period corresponding to the first period of the pressure change. In the second period corresponding to the second period of the pressure change, the pressure in the vessel has declined below the equilibrium hydrate dissociation pressure and the hydrate begins to be dissociated. The rates of the gas production remain steady. In the third period corresponding to the third period of the pressure change, the pressure remains constant, and is the same with the set production 


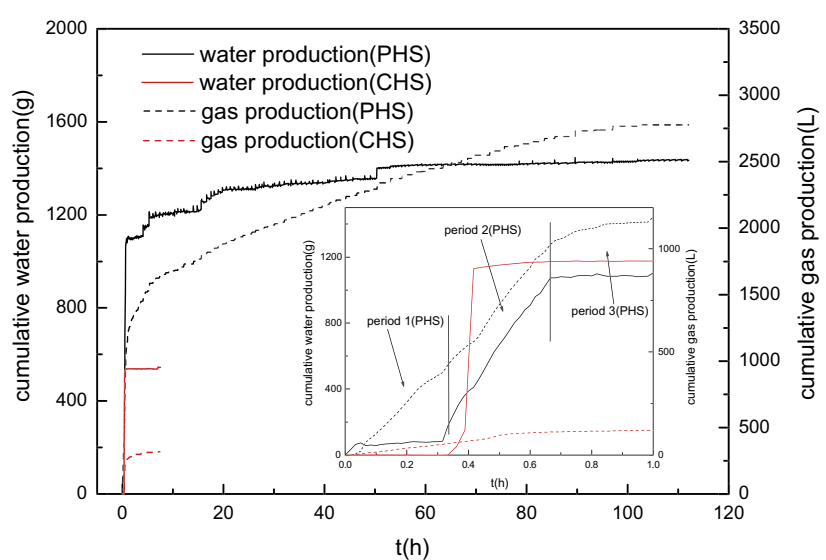

Fig. 5. Cumulative gas and water production during experiments with PHS and CHS.

pressure. The hydrate is continuously dissociated, and the gas production rate is remarkably lower than those in the free gas production and the mixed gas production periods, and eventually declines to zero. When the rate equals to zero, the dissociation is completed.

It can be seen from Fig. 5 that, the gas production time with the PHS is much longer than that with the CHS, which illustrates that the size of the hydrate reservoir has a significant effect on the gas production and gas production rate. The free gas and mixed gas production processes, which are corresponding to the depressurizing period, last $40 \mathrm{~min}$ and $36.5 \mathrm{~min}$ with the PHS and the CHS, respectively. The duration of this period with PHS is slightly longer than that with CHS because the pressure reduction rate with the PHS is lower than that with the CHS. In the gas production process from hydrate dissociation, which is corresponding to the steady pressure period, the durations with the PHS and CHS are $6081 \mathrm{~min}$ and $300 \mathrm{~min}$, respectively. It can be found that the duration with the PHS is approximately 20 times as many as that with CHS in the period of gas production from the dissociation. This illustrates that the size of the hydrate reservoir has a small influence on the time required for the free gas and mixed gas production, while it has a quite significant impact on the time required for the dissociated gas production.

Fig. 6 shows the cumulative gas production and the average gas production rates in the first, second and third gas production periods in the experiments with the PHS. It can be seen from Fig. 6 that the cumulative gas production in the third period (the period of the gas production from hydrate dissociation) is much higher than those in the first and second periods (the periods of the free gas production and the mixed gas production), which accounts for

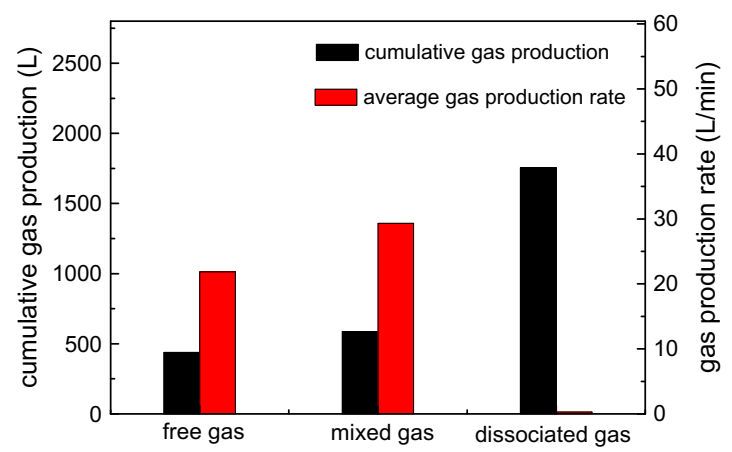

Fig. 6. Cumulative gas production and gas production rates in different production periods with PHS. approximately $63 \%$ of the total gas production. However, the average gas production rate in the third period is low, which inhibits the production efficiency in the whole production process. Therefore, the enhancement of the production rate in the third period is a key factor to obtain the high gas production efficiency from hydrate reservoir by depressurization. The similar behavior can be observed by the experiments with the CHS. In order to analyze the gas production change in the third period, we calculated the gas production rates and the gas production time at the different percentages of the total cumulative gas production in the third period in the experiments with each of the PHS and CHS, as shown in Figs. 7a and 7b. It can be seen from Figs. 7a and 7b that the gas production rate at the first $10 \%$ of the total cumulative gas production in the third period with each of the vessel is very high. With the hydrate dissociation progressing, the gas production rate dramatically drops. Particularly, from $60 \%$ to $100 \%$ of the dissociated gas production, the gas production rate is quite low and continuously drops slowly, and the production time takes up approximately $70 \%$ of the whole time of the dissociated gas production. Therefore, the production efficiency of the dissociated gas of the last $40 \%$ is rather low. Thus, it is proposed that other methods should be used to enhance the recovery efficiency for the production of the dissociated gas of the last $40 \%$.

In order to further figure out the effect of the size of the hydrate reservoir on the gas production behavior, the gas production rates and the production time at the different percentages of the total cumulative dissociated gas production $(x)$ in the dissociated gas production period with the PHS and CHS are investigated. Because the effective volumes of the PHS and CHS are different, the direct comparison of the gas production rates for the experiments with the two hydrate simulators is not reasonable. Therefore, we calculated the gas production rate per liter in the hydrate-bearing sediment in the vessel $\left(R_{s}\right)$ with each of the two hydrate simulators. As shown in Table 1 , the $R_{S}$ decreases and the production time $(t)$ increases with the increase of the $x$ in the experiments with each of the two hydrate simulator. It can be also seen from Table 1 that the $R_{S}$ with PHS is much smaller than that with the CHS at the same $x$, and thus the $t$ with PHS is much longer than those with the CHS at the same $x$. We also calculated the ratios of the $R_{S}$ with the PHS to the $R_{S}$ with the CHS, $R_{P C}$, and the ratios of the $t$ with the PHS to the $t$ with the CHS, $t_{P C}$, at the different $x$. The $R_{P C}$ is $0.295,0.161,0.124$, $0.097,0.082$ and 0.081 when the $x$ is $10 \%, 20 \%, 30 \%, 40 \%, 60 \%$, and $80 \%$, respectively. The $t_{P C}$, are $6.36,11.57,15.03,19.22,22.59$ and 22.43 when the $x$ is $10 \%, 20 \%, 30 \%, 40 \%, 60 \%$, and $80 \%$, respectively. It can be found that the $R_{P C}$ decreases and the $t_{P C}$ increases with the $x$ increasing from $0 \%$ to $40 \%$. As the $x$ continuously increases from $40 \%$ to $100 \%$, the $R_{P C}$ and $t_{P C}$ remain almost constant.

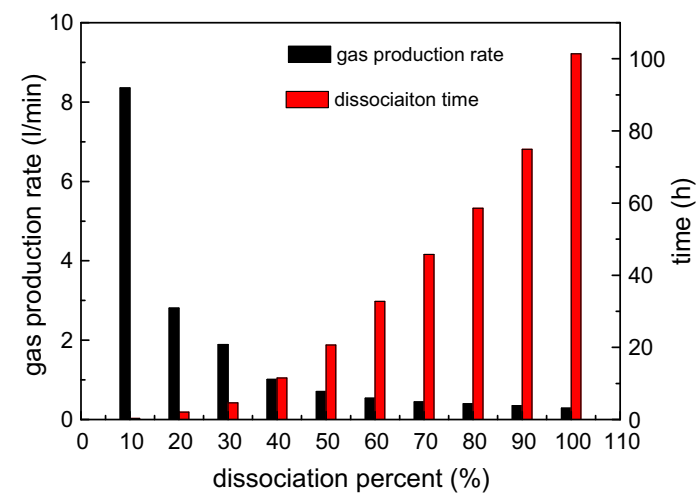

Fig. 7a. Gas production rates and production time at different percentages of total cumulative gas production in dissociated gas production period in experiments with PHS. 


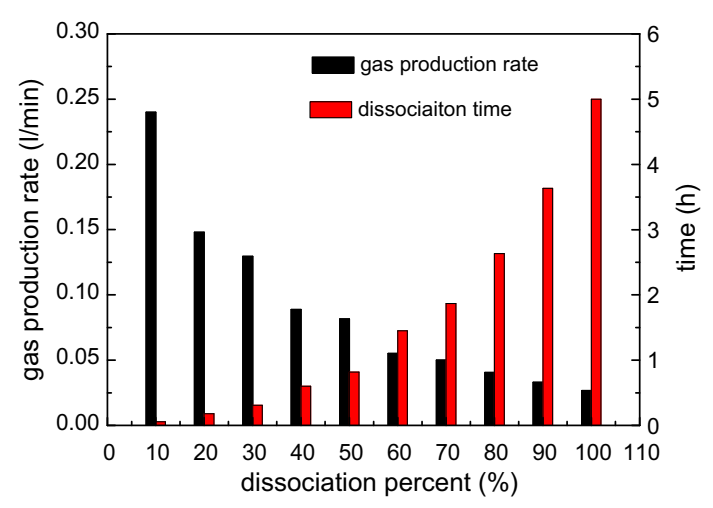

Fig. 7b. Gas production rates and production time at different percentages of total cumulative gas production in dissociated gas production period with experiments with CHS.

This illustrates that, in the dissociated gas production period, the reduction magnitude of the $R_{s}$ and the increase magnitude of the $t$ are higher with the bigger size of the reservoir with $x$ increasing from $0 \%$ to $40 \%$. However, the values of the individual $R_{s}$ and $t$ with either the large size of the hydrate reservoir or the small one remain almost constant with $x$ increasing from $40 \%$ to $100 \%$.

\subsection{Water production}

Fig. 5 also shows the cumulative water production during the experiments with the PHS and CHS. As shown in Fig. 5, In the starting stage (0.0-3.0 $\mathrm{min}$ ) of the free gas release period (the first period of gas production), there is some water produced as the gas releases for the experiment with the PHS, which is possibly from the water inside the well in the vessel. Afterwards, there is no water production from $3.0 \mathrm{~min}$ to $20.0 \mathrm{~min}$. The water continues to be produced after $20.0 \mathrm{~min}$. The reason is that, in the depressurizing process, which is corresponding to the first and the second periods of the gas production, the water moves from the surroundings toward the wellhead in the center of the vessel, and fills the pores in the near-well region, and then is removed out from the production well under the effect of a driving force for the water movement (the discrepancy between the pressure in the vessel and the set production pressure). In the mixed gas production period, the system pressure has declined below the equilibrium hydrate dissociation pressure and the hydrate begins to be dissociated. The water continues to be produced with the steady rate of the water production. In the third period of gas production, the system pressure is equal to the set production pressure. The water production rate also decreases dramatically. The water production is the result from the effect of the gas entraining the water in the process of the gas production other than the effect of the driving force, the difference between the system pressure and the set production pressure, which is equal to zero. As the hydrate is continuously dissociated into gas and water in the period, the water is slowly produced continuously, and the water production rate is much low and decreases continuously with the gas production rate reducing. However, in the experiment with the CHS, the water production with the quite high rate mainly occurs in the first and second periods of gas production. In the third of gas production, little water is produced. Table 1 also gives the water production per liter in the hydrate-bearing sediment in the vessel $\left(M_{w}\right)$ with each of the two hydrate simulators. In the depressurizing period corresponding to the first plus second periods of the gas production or pressure change, the water is produced by the effect of the driving force (the difference between the system pressure and the set production pressure). It can be seen that the $M_{w}$ in the experiment with the PHS is obviously lower than that with the CHS in the depressurizing period. It may be due to the fact that the hydrate-bearing sediment with the larger size results in the bigger flow resisting force per unit length at the fixed driving force, and thus results in the reduction of the water flow ability. Therefore, the water is more difficult to move to the wellhead with the larger size hydrate reservoir. In the steady pressure period corresponding to the third period of gas production or the pressure change, the $M_{w}$ in the individual experiment with the PHS and CHS is remarkably lower than that in the depressurizing process. However, the $M_{w}$ in the experiment with the PHS is higher than that with the CHS in the steady pressure period. It is due to the fact that, on one hand, almost all the water has been produced in the depressurization period with the CHS, as shown in Fig. 5; on the other hand, small amount of water is produced in the depressurization period with the PHS, and thus considerable water remaining in the sediment is removed out of the well under the effect of the gas entraining the water in the steady pressure period.

\subsection{Temperature profiles and spatial distributions}

Fig. 8 shows the temperature profiles of T25B, T17B, T9B, and T1B during the experiment with the PHS. As a typical example, the temperature change at point $9 \mathrm{~B}$ in the vessel consists of the four periods, as shown in Fig. 8. The first period of the temperature change $(0-0.33 \mathrm{~h})$ corresponds to the first stage of the pressure change and the stage of the free gas release in Figs. 4 and 5. Because there is no hydrate dissociation, the temperature does not change significantly. The second period is between 0.33 and $0.67 \mathrm{~h}$, which corresponds to the second stage of the pressure change and the mixed gas production stage. In this period, the temperature decreases dramatically. It is attributed to the fact that the rapid hydrate dissociation requires to absorb immediately considerable heat from the surroundings, causing the temperature in the system to decline rapidly to the lowest point. The third plus forth periods of the temperature change correspond to the third stage of the pressure change and the stage of the dissociated gas production in Figs. 4 and 5. The third period is between 0.67 and $50.6 \mathrm{~h}$. In this period, the hydrate dissociation process continues and the temperature at 9B in the vessel basically keeps around this steady lowest value. It illustrates that the heat needed for the hydrate dissociation is equivalent to that supplied from the ambient in this period. The forth period is from $50.6 \mathrm{~h}$ to the end of the experiment. In the forth period, the hydrate dissociation at 9B becomes slow and trends to end and the temperature gradually rises from

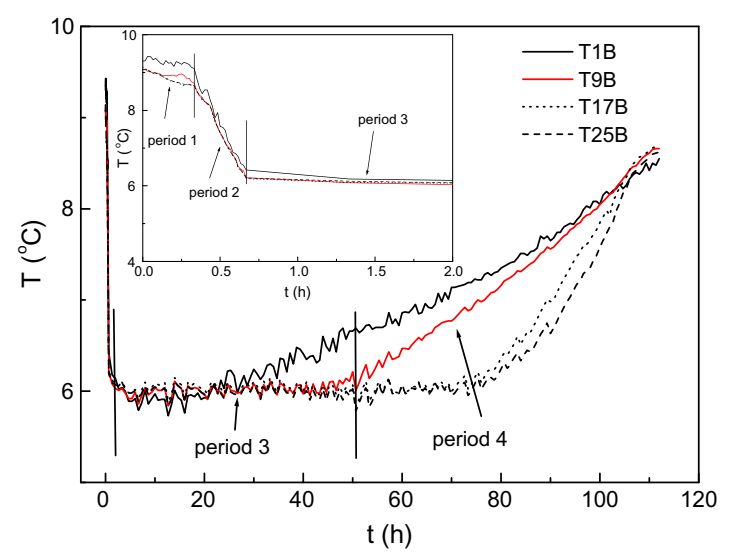

Fig. 8. Temperature profiles at different measuring points during experiments with PHS. 
the lowest temperature point to the environmental temperature. In this period, the heat transferred from the ambient is more than the heat required for hydrate dissociation. It can be seen from Fig. 8 that the temperatures at the different measuring points change nearly in-step in the first two periods. However, in the third and forth periods, the temperature from point 1B to point 25B successively increases gradually. The system temperature change is caused by the hydrate dissociation. In the first and second periods, the hydrate dissociation mainly results from the pressure reduction in the system. Because of the high porosity and permeability of the sediment, the magnitude of the pressure reduction at each measuring point is the same, and thus leads to the degree of the temperature change at each measuring point being the same. However, in the third and forth periods, the temperature change resulted from the hydrate dissociation is controlled by the heat transfer from the ambient. The heat supplied from the ambient (water bath) is successively transferred from the inner wall to the center of the vessel. The similar phenomena can be seen from other points in each layer from the surroundings to the center of the vessel.

Fig. 9 shows the temperature spatial distribution over time in hydrate reservoir during the experiment with PHS. In the work, we use the temperature difference between the real-time temperature in the production process and the temperature at the starting time of the hydrate production experiment to describe the temperature characteristics. Fig. 9a gives the temperature distribution at the 7 th min, which is during the free gas release process and the first period of the temperature change. It can be seen from Fig. 9a that the temperatures at various measuring points in the vessel do not change obviously, which can also be seen in Fig. 8 . Fig. $9 \mathrm{~b}$ gives the temperature spatial distribution at the $31 \mathrm{st}$ min, which is in the second period of the temperature change (see Fig. 8). As seen from Fig. 9b, generally, the temperatures decrease compared with those at the starting time of the gas production because of the endothermic reaction of the hydrate dissociation in the hydrate reservoir. The drop of temperature at different regions is almost the same. It is as a result of the hydrate dissociation, which is caused by the pressure reduction, occurring in the whole sediments in the vessel, as discussed above. Fig. 9c shows the spatial distribution of the temperature at the time when the pressure in the vessel has reached the set production pressure, the 1145th min, which is within the third period of the temperature change. At the 1145th min, the hydrate is dissociated continuously, and the temperatures in the different regions reach their individual lowest values. It can be seen that the lowest temperatures at the different measuring points in the vessel are similar. Fig. 9d and e give the temperature spatial distributions at the 4500th and 6000th min, respectively, which are within the forth period of the temperature change. The temperatures in the various regions have some discrepancies and the temperatures in the near-well region are lower than those in the far-from-well region. It is due to the fact that the heat supplied from the circumstance is successively transferred from the inner wall to the center of the vessel.

In the experiment with the CHS [22], the temperature changes at various measuring points have an increase period. However, in this work, there is no such a temperature increase period. As shown in Table 1, the water production per liter in the hydratebearing sediment in the vessel in the PHS is significantly lower than that in the CHS in the depressurizing period. In our previous work [22] it has been illustrated that the hydrate reformation is caused by the liberation of the water encased in the formerly forming hydrate and the water flow under the effect of the driving force (the discrepancy between the pressure in the vessel and the set production pressure) when the system pressure is higher than the equilibrium hydrate dissociation pressure. The flowing water contacts methane gas in the sediment to form the hydrate again, causing the rise of the system temperature as a result of the effect of the heat released from the hydrate formation [22]. However, as explained on the above, under the fixed driving force, the flow resisting force per unit length is bigger with the increase of size of the hydrate-bearing sediment, resulting in the reduction of the water flow ability. This also means the decrease of the contact area of the water and gas, resulting in the great reduction of the possibility of the hydrate formation. Therefore, this is reason that there

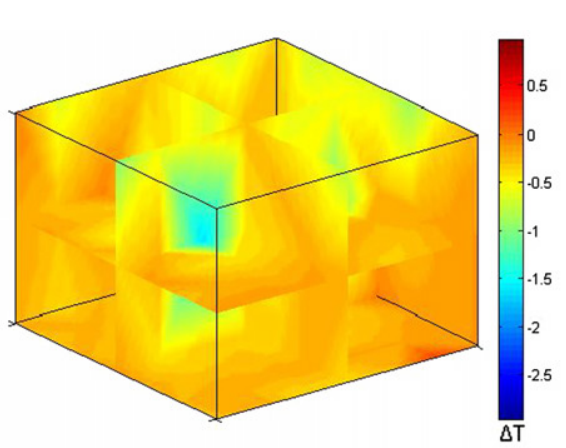

(b) $31 \mathrm{~min}$

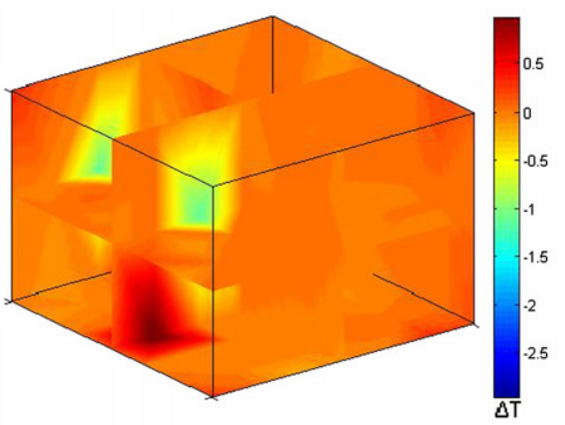

(a) $7 \mathrm{~min}$

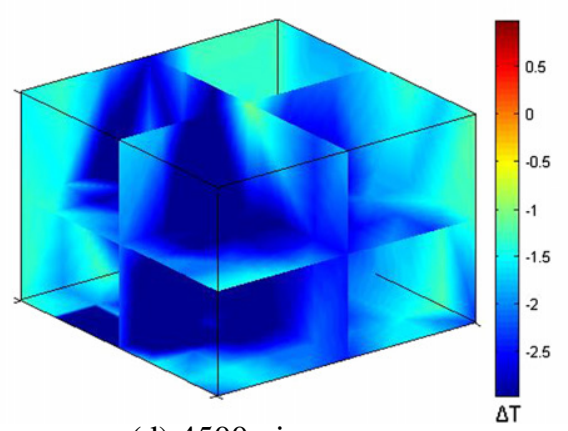

(d) $4500 \mathrm{~min}$

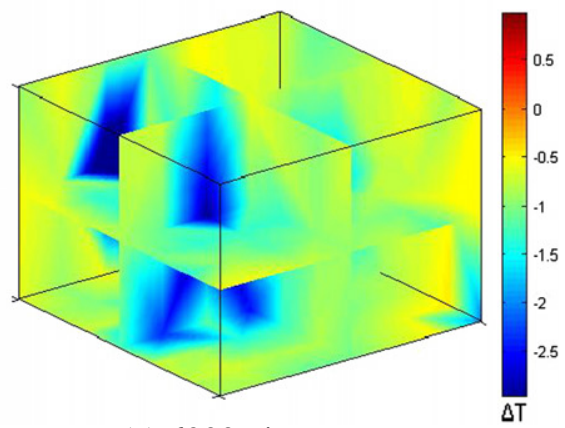

(e) 6000min

(c) $1145 \mathrm{~min}$

Fig. 9. Temperature spatial distributions over time in hydrate reservoir with PHS. 


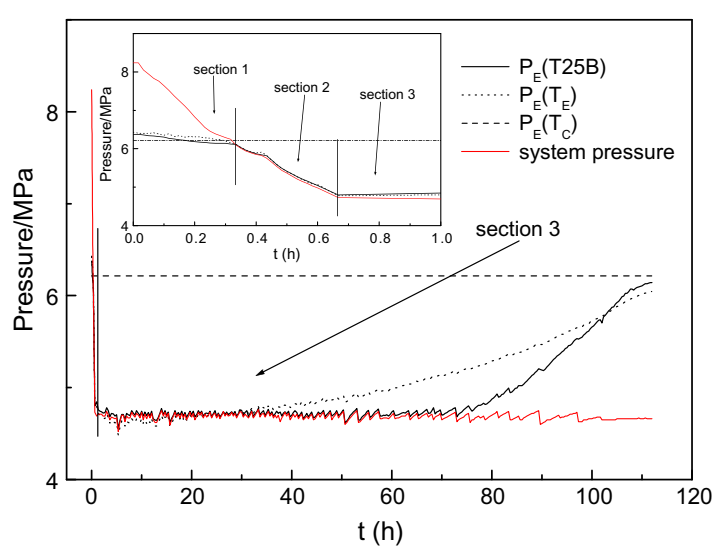

Fig. 10. Equilibrium dissociation pressure at mean temperature, temperature of $25 \mathrm{~B}$ in the vessel and ambient temperature, and outlet pressure versus time during experiment with PHS.

is no hydrate reformation and the temperature increase period in the experiment with the PHS with the quite large effective volume (the effective volume of the PHS is approximately 23 times as large as that of the CHS).

The hydrate dissociation results in a remarkable decrease of the temperature in the system, and furthermore causes the decrease of the corresponding equilibrium dissociation pressure. Thus, the effectiveness of the depressurizing dissociation is lowered. To investigate into the effect of the temperature change on the gas production by depressurization, we give the changes of the equilibrium dissociation pressure at the mean temperature, temperature of $25 \mathrm{~B}$ in the vessel and ambient temperature with time during the experiment with the PHS, as shown in Fig. 10. As a comparison, the system pressure change is also given in Fig. 10. In Fig. 10, $T_{E}$ is the mean temperature in the system, $T_{C}$ is the ambient temperature and $P_{E}$ is the equilibrium hydrate dissociation pressure at the corresponding temperature, which is calculated by the fugacity equation given by Li et al. [26]. It can be seen from Fig. 10 that with the decrease of the system pressure in the early stage of the hydrate dissociation (the second section of the pressure change), the equilibrium hydrate dissociation pressures at the mean temperature in the system and the temperature at point $25 \mathrm{~B}$ also decrease, and the pressure values almost are equal to the system pressure. Therefore, it is found that the driving force for the hydrate dissociation (the difference between the equilibrium hydrate dissociation pressure and the system pressure) is quite small during this period and much less than the difference between the system pressure and the equilibrium pressure at the ambient temperature. This demonstrates that the sensible heat of the hydrate reservoir is spent by the hydrate dissociation, and the hydrate dissociation is mainly controlled by the rate of the pressure reduction during a very short period. Later, the equilibrium pressure corresponding to the mean temperature in the vessel gradually increases. It is due to the fact that with the reduction of the amount of the hydrate, the heat required for the hydrate dissociation is gradually less than that supplied from the ambient. The equilibrium pressure corresponding to the temperature at point $25 \mathrm{~B}$ is consistent with the system pressure for a long time. It is because point $25 \mathrm{~B}$ is at the center of the vessel, where the supplied heat reaches last, and therefore the temperature rise is last. In the third period of the gas production, the pressure in the vessel decreases to the set production pressure. Because almost all the sensible heat in the reservoir is spent in the second period of the gas production, the gas production rate is low in the third period. Actually, the heat conduction from the ambient is main driving force to dissociate the hydrate in the period. The results are in agreement with those of Kono et al. [27] and those with the CHS [22]. The characteristics of the temperature change in the hydrate reservoir with the CHS in the whole gas production process are similar with those with PHS [22].

\subsection{Reservoir resistance}

Generally, the resistivity of the hydrate is higher than that of water and is lower than that of gas in the hydrate/gas/water system in the sediment. In the process of gas production from the hydrate reservoir, the hydrate is gradually dissociated into water and gas, causing the change of the resistance in the sediment with time. Therefore, the resistance can be used to characterize the change of the gas hydrate reservoir in the process of hydrate dissociation [28].

Fig. 11 shows the resistance ratio spatial distribution over time during hydrate dissociation in the PHS. The resistance ratio is the ratio of the resistance in the gas production process to the resistance at the starting time of the hydrate dissociation experiment. Fig. 11a gives the resistance ratio spatial distribution at the 7th min, which is within the free gas release period and before the water production. As seen, the resistance ratios at various measuring points in the vessel are the same and have little change. It is because in the free gas release process, the hydrate is not dissociated, and the water and hydrate saturation in the vessel does not change remarkably. Fig. 11b gives the resistance ratio spatial distribution at the $31 \mathrm{st}$ min, which is in the mixed gas production process. In this period, the hydrate has begun to be dissociated, resulting in the decrease of the resistances in the sediment. It can be also seen from Fig. 11b that the resistance ratios in the bottom region are higher than those in the upper region. The reason may be as follows: Before the gas production experiment, the hydrate formation process lasts approximately $1451.5 \mathrm{~h}$. In the formation process, the water flows to the bottom region in the vessel because of the gravity, causing the hydrate saturation in the bottom region is higher than that in the upper region before the gas production experiment. In the mixed gas production process, the hydrate in the vessel is dissociated by absorbing the sensible heat of the sediment. As shown in Fig. 9b, the temperatures in the different regions in the vessel have the similar drop degree, illustrating that similar sensible heat is spent in the different regions. The similar sensible heat causes the similar amount of the hydrate dissociation in the different regions. Because the hydrate saturation in the bottom region is higher than that in the upper region before the gas production experiment, relatively, the percent of the hydrate dissociated in the upper region is higher than that in the bottom region, causing the degree of the resistance decrease is bigger in the upper region. In the gas production experiment with the $\mathrm{CHS}$, the resistance changes in the reservoir are affected by the hydrate dissociation and the flows of the water and gas [22]. In the depressurizing process in the CHS, there are higher resistances in the bottom region because the water flows upward the upper of the vessel, resulting in the increase of the gas content and the decrease of the water content in the bottom region [22]. In the experiment in the PHS, the water production per liter in the hydrate-bearing sediment is significantly lower than that in the CHS. Thus, the effect of the water flow on the resistance change is quite weak, and the resistances in the sediment mainly change with the decrease of the hydrate saturation as a result of the dissociation.

Fig. 11c and d give the resistance distributions at the 1145th and 4500th min, respectively, which are within the dissociated gas production period. It can be seen from Fig. 11c and $d$ that the resistances in the vessel continuously decrease and the resistance ratios in the bottom region are also higher than those in the upper region. Fig. 11e gives the resistance distribution at the 6000th min, when the hydrate has been almost completely decomposed. At this 


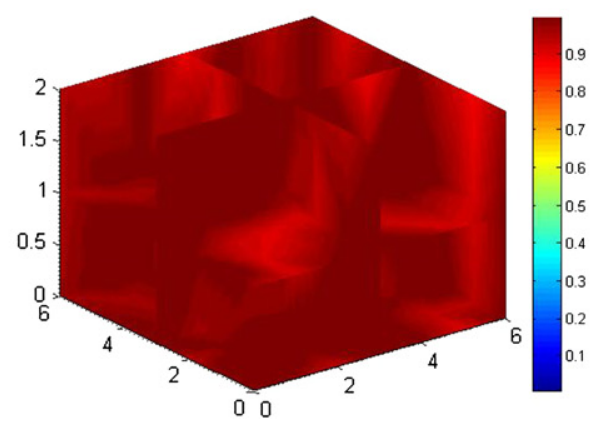

(a) $7 \mathrm{~min}$

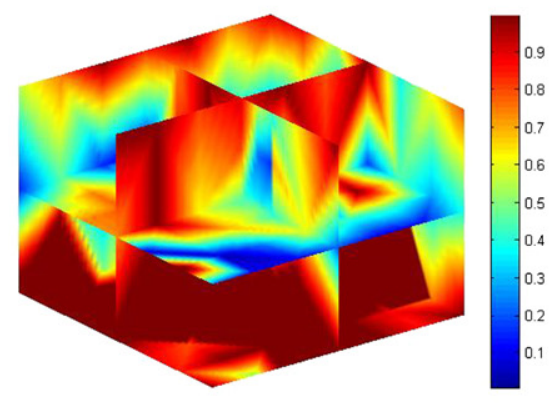

(b) $31 \mathrm{~min}$

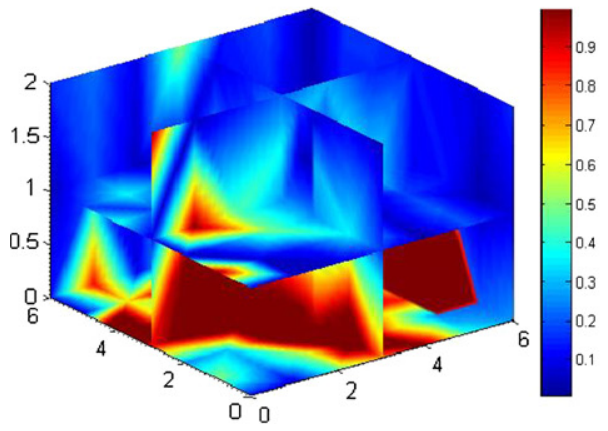

(c) $1145 \mathrm{~min}$

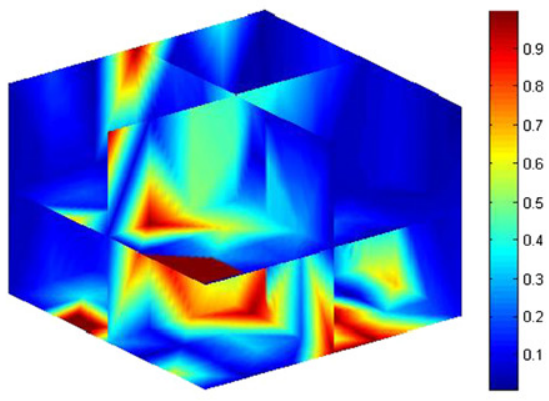

(d) 4500min

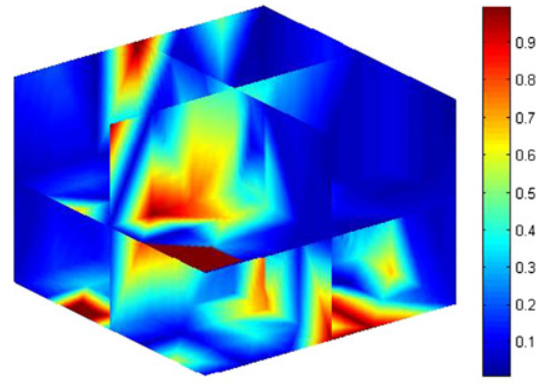

(e) $6000 \mathrm{~min}$

Fig. 11. Resistance ratio spatial distributions over time in hydrate reservoir with PHS.

time, the resistances in the different measuring points in the vessel decline remarkably, compared with those at the beginning of the gas production experiment, and generally, the resistance ratios in the most regions are approximately the same. Similar to the phenomenon in the depressurizing process, the resistances in the vessel are also mainly affected by the hydrate dissociation. In the experiment in the CHS, the resistance ratios in the bottom region are still higher than those in the upper region in the hydrate dissociation period. However, the differences of the resistance ratios between the bottom and upper regions reduce. It is because the water production has been completed in the period, and thus some water moving to the upper region of the vessel falls back to the bottom region due to gravity. The resistance value at each measuring point in the CHS in the steady pressure period is relatively lower than that in the depressurizing period [22].

\section{Summary and conclusions}

In this work, we investigate into the gas production behavior of methane hydrate in the sediment by depressurization in a novel pilot-scale hydrate simulator (PHS). By comparison with the results obtained at the similar experimental condition by using a threedimensional cubic hydrate simulator (CHS) with the effective volume of $5.8 \mathrm{~L}$, the investigation into the effect of the size of the hydrate reservoir on the gas production behavior are carried out. The following conclusions are drawn:

(1) The gas production process from the hydrate reservoir in the experiment with each of the two simulators consists of three periods: the free gas production, mixed gas (free gas and gas dissociated from the hydrate) production and gas production from the hydrate dissociation. The free gas and mixed gas production periods are mainly controlled by the pressure reduction rate. The heat conduction from the ambient is main driving force to dissociate the hydrate in the dissociated gas production period.

(2) The cumulative gas production in the period of the gas production from hydrate dissociation with each of the PHS and CHS is much higher than those in the periods of the free gas production and the mixed gas production. However, the average gas production rate in the period is low. Particularly, from the $60 \%$ to $100 \%$ of the dissociated gas production, the gas production rate is quite low, and the production time takes up approximately $70 \%$ of the whole the time of the dissociated gas production. Thus, it is proposed that other methods should be used to enhance the recovery efficiency for the production of the dissociated gas of the last $40 \%$.

(3) In the dissociated gas production period, the reduction magnitude of the gas production rate per liter and the increase magnitude of the production time are higher with the bigger size of the reservoir with the percentages of the total cumulative dissociated gas production $(x)$ increasing from $0 \%$ to $40 \%$. However, both the gas production rate per liter and production time remain almost constant with $x$ increasing from $40 \%$ to $100 \%$ with either the large-size hydrate reservoir or the small one.

(4) It is found that the time duration for gas production with the PHS is approximately 20 times as many as that with CHS in the dissociated gas production period, illustrating that the size of the hydrate reservoir has a significant effect on the gas production rate and time, which mainly shows in the dissociated gas production period other than the free gas and mixed gas production periods.

(5) With the CHS, the water production with the relative high rate mainly occurs in the free gas production and mixed gas production periods. In the dissociated gas production 
period, little water is produced. With the PHS, the water production with the low rate occurs in the whole gas production process. In the free gas production and mixed gas production periods, the water production per liter with the PHS is much lower than that with the CHS. In the dissociated gas production period, the water production per liter with the PHS is higher than that with the CHS.

(6) The temperature change at each measuring point in the hydrate reservoir during the gas production from the hydrate with the PHS consists of four periods. The first period represents the free gas releasing, which is practically isothermal. In the second period corresponding to the mixed gas production period, the temperatures in the vessel decrease dramatically due to the hydrate dissociation. In the third period corresponding to the dissociated gas production period, the temperature at each measuring point remains constant. In the forth period, which is also in the dissociated gas production period, the hydrate has been almost dissociated completely and the temperatures gradually increase to the environmental temperature. The temperature change tendency with the CHS is the same with that with the PHS except that there is also a period of the temperature increase on account of the hydrate reformation in the system in the free gas release period with the CHS.

(7) The resistances in the hydrate reservoirs decrease as the gas production progressing with the PHS and CHS, and the resistance ratios in the bottom region are higher than those in the upper region in the hydrate dissociation processes. The resistance changes in the reservoir with the PHS are mainly affected by the hydrate dissociation, and those with the CHS is mainly impacted by the hydrate dissociation and the flows of the water and gas.

\section{Acknowledgments}

This work was supported by National Natural Science Foundation of China (Grants 51076155 and 51004089) and Science \& Technology Program of Guangdong Province (Grant 2009B050600006), which are gratefully acknowledged.

\section{References}

[1] Kumar S, Kwon HT, Choi KH, Lim W, Cho JH, Tak K, et al. LNG: an eco-friendly cryogenic fuel for sustainable development. Appl Energy 2011;88:4264-73.

[2] Aspelund A, Gundersen T. A liquefied energy chain for transport and utilization of natural gas for power production with $\mathrm{CO}_{2}$ capture and storage - Part 1 . Appl Energy 2009;86:781-92.

[3] Chatti I, Delahaye A, Fournaison L, Petitet JP. Benefits and drawbacks of clathrate hydrates: a review of their areas of interest. Energy Convers Manage 2005;46:1333-43.

[4] Eslamimanesh A, Mohammadi AH, Richon D, Naidoo P, Ramjugernath D. Application of gas hydrate formation in separation processes: a review of experimental studies. J Chem Thermodyn 2012;46:62-71.
[5] Lee J. Experimental study on the dissociation behavior and productivity of gas hydrate by brine injection scheme in porous rock. Energy Fuels 2010;24(1):456-63.

[6] Makogon YF, Holditch SA, Makogon TY. Natural gas-hydrates - a potential energy source for the 21st century. J Petrol Sci Eng 2007;56(1-3):14-31.

[7] Riedel M, Long PE, Collett TS. Estimates of in situ gas hydrate concentration from resistivity monitoring of gas hydrate bearing sediments during temperature equilibration. Mar Geol 2006;227(3-4):215-25.

[8] Englezos P, Lee JD. Gas hydrates: a cleaner source of energy and opportunity for innovative technologies. Korean J Chem Eng 2005;22(5):671-81.

[9] Englezos P. Clathrate hydrates. Ind Eng Chem Res 1993;32:1251-74.

[10] Sung WM, Huh DG, Ryu BJ, Lee HS. Development and application of gas hydrate reservoir simulator based on depressurizing mechanism. Korean J Chem Eng 2000;17(3):344-50.

[11] Moridis GJ, Reagan MT. Strategies for gas production from oceanic class 3 hydrate accumulations. In the offshore technology conference. 2007; 18865.

[12] Moridis GJ, Collett TS, Boswell R, Kurihara M, Reagan MT, Koh C, et al. Toward production from gas hydrates: current status, assessment of resources, and simulation-based evaluation of technology and potential. SPE Reservoir Eval Eng 2009;12(5):745-71.

[13] Moridis GJ, Reagan MT, Kim SJ, Seol Y, Zhang K. Evaluation of the gas production potential of marine hydrate deposits in the Ulleung basin of the Korean east sea. SPE J 2009;14(4):759-81.

[14] Sun X, Nanchary N, Mohanty KK. 1-D modeling of hydrate depressurization in porous media. Transp Porous Med 2005;58(3):315-38.

[15] Song YC, Liang HF. 2-D numerical simulation of natural gas hydrate decomposition through depressurization by fully implicit method. China Ocean Eng 2009;23(3):529-42.

[16] Tang LG, Li XS, Feng ZP, Li G, Fan SS. Control mechanisms for gas hydrate production by depressurization in different scale hydrate reservoirs. Energy Fuels 2007;21(1):227-33.

[17] Oyama H, Konno Y, Masuda Y, Narita H. Dependence of depressurizationinduced dissociation of methane hydrate bearing laboratory cores on heat transfer. Energy Fuels 2009;23:4995-5002.

[18] Lee J, Park S, Sung W. An experimental study on the productivity of dissociated gas from gas hydrate by depressurization scheme. Energy Convers Manage 2010;51(12):2510-5.

[19] Haligva C, Linga P, Ripmeester JA, Englezos P. Recovery of methane from a variable-volume bed of silica/hydrate by depressurization. Energy Fuels 2010;24:2947-55.

[20] Sakamoto Y, Kakumoto M, Miyazaki K, Tenma N, Komai T, Yamaguchi T, et al. Numerical study on dissociation of methane hydrate and gas production behavior in laboratory-scale experiments for depressurization: Part 3 Numerical study on estimation of permeability in methane hydrate reservoir. Int J Offshore Polar Eng 2009;19(2):124-34.

[21] Kono HO, Narasimhan S, Song F, Smith DH. Synthesis of methane gas hydrate in porous sediments and its dissociation by depressurizing. Powder Technol 2002;122(2-3):239-46.

[22] Li XS, Zhang Y, Li G, Chen ZY, Wu HJ. Experimental investigation into the production behavior of methane hydrate in porous sediment by depressurization with a novel three-dimensional cubic hydrate simulator. Energy Fuels 2011;25(10):4497-505.

[23] Li G, Moridis GJ, Zhang K, Li XS. The use of huff and puff method in a single horizontal well in gas production from marine gas hydrate deposits in the Shenhu Area of the South China Sea. J Petrol Sci Eng 2011;77(1):49-68.

[24] Moridis GJ, Reagan MT, Boyle KL, Zhang K. Evaluation of the gas production potential of challenging hydrate deposits. In: TOUGH symposium; 2009.

[25] Li G, Li XS, Tang LG, Zhang Y. Experimental investigation of production behavior of methane hydrate under ethylene glycol injection in unconsolidated sediment. Enger Fuels 2007;21:3388-93.

[26] Li XS, Zhang Y, Li G, Chen ZY, Yan KF, Li QP. Gas hydrate equilibrium dissociation conditions in porous media using two thermodynamic approaches. J Chem Thermodyn 2008;40:1464-74.

[27] Konno Y, Masuda Y, Hariguchi Y, Kurihara M, Ouchi H. Key factor for depressurization-induced gas production from oceanic methane hydrate. Energy Fuels 2010;24:1736-44.

[28] Hyndman RD, Yuan T, Moran K. The concentration of deep sea gas hydrates from downhole electrical resistivity logs and laboratory data. Earth Planet Sci Lett 1999;172(1-2):167-77. 